\title{
Ricardo Palma y el Problema de la Poesía Romántica
}

4 $\mathrm{N}$ su soneto, "Romanticismo", 1 Ricardo Palma expone sardónicamente 1 su concepción de los límites de la poesía frente a la vida, mientras que inconscientemente muestra sus propias limitaciones de poeta. En el soneto, Palma encadena una serie de metáforas hiperbólicas para enamorar a una señorita, la cual resulta su mejor crítico:

-Tal dije a Carmen. No mordió el anzuelo, y contestó: -iPalabras de poeta!

Vaya usted con la música a otra parte.

Esta afirmación de una dicotomía entre la poesía y la realidad muestra una actitud ambigua hacia el romanticismo, el cual, para 1865, poseía el monopolio del uso de la voz "poesía". La actitud de Palma implica una crítica contra lo desmedido del movimiento, pero al mismo tiempo acepta la definición romántica más vulgar de la poesía: una extravagancia al servicio de las emociones.

Así, en Pasionarias, el deber de ser realista se impone sobre el poema para burlarse de la "poesía" contenida en él. Al objeto de conformarse con la realidad - sobre todo con la realidad política- algunos poemas de la colección llegan a ser didácticos a la manera neo-clásica (aunque no en su estilo). Palma no se burla del romanticismo parodiándolo simplemente, lo cual representaría un criterio literario, sino que, por medio del juicio de Carmen, se burla de la poesía misma, por razones extraliterarias.

De aquí surge un conflicto. De un lado está la imaginación poética romántica: "Palabras de poeta!" lo que equivale a decir "exageraciones".

1 De Pasionarias, en Ricardo Palma, Poesias completas (Barcelona y Buenos Aires, 1911), pp. 101-140. Todos los poemas de Palma citados en este estudio se encuentran en Pasionarias. 
De otro lado está el deber de ser realista, de desconfiar de esas palabras de poeta. Veremos cómo en otros poemas de Palma este deber se convierte en la expresión de un concepto neo-clásico del papel de la poesía: ésta debe ser un instrumento de enseñanza, aunque lo enseñado sea la política romántico-liberal. Mas la expresión de este conflicto carece de vigor, pues la imaginación que Palma muestra en sus versos es débil, y su pensamiento tiende a caer en lo pedestre.

No hay razones para creer que en "Romanticismo" Palma intentara inventar metáforas ridículas desde un punto de vista literario. "Eres ángel venida de otra esfera / la tierra a engalanar con tu hermosura" es un concepto vacio de sentido si no se elabora (y Palma no lo elabora); pero sí tiene posibilidades poéticas y por consiguiente no sirve para satirizar la vacuidad del romanticismo. La sátira la hace Carmen, quien no la emplea con fines literarios sino como la voz de la realidad que se opone a la literatura. De hecho, expresa su desdén por la poesía en un clisé de lo más banal.

Aunque estemos equivocados en lo que acabamos de decir y la intención de Palma fuera la de parodiar el romanticismo en esos versos, no lo estamos en nuestra crítica del poema porque, para tener éxito con un esquema dialéctico como el de "Romanticismo", es necesario expresar lo mejor posible tanto la tesis como la antítesis. Desgraciadamente, la poesía está mal representada aquí por las efímeras y extravagantes metáforas de Palma.

Este, en otros poemas de Pasionarias, insiste sobre el mismo tema: no que la poesía romántica sea mala pocsía sino que la poesía (que es, por definición, romántica) es mala política. Por consiguiente, Palma trata de cambiar el papel de la poesía, devolviéndola a su antigua función de instruir y deleitar, para que no sea "poética".

Así, el autor de "Definición", que explicó "el misterio... del amor" a "la niña de ojos azules" y que después define las lágrimas como ". . las perlas / que va a buscar el dolor, / en el profundo océano / que se llama corazón", cede al que repite "la voz de Dios que dice, amenazante: / ¡Vé adelante, Ashavero, vé adelante!" Lo que une estos trozos, a primera vista $\tan$ dispares, es el fuerte sentido del deber. Hasta el sentimentalismo se ve de esta manera: Palma se esfuerza por buscar las lágrimas en vez de dejarlas saltar de los ojos.

En el poema "Fatum", del que proceden los dos últimos versos citados, el mandato de seguir viviendo aunque la "existencia está maldita" refleja otra vez la idea del deber. En la literatura romántica la figura del judío errante suele interesar por los sufrimientos que padece; pero, en 
este poema, las palabras del Señor realzan el papel de Ashavero como ejemplo de obediencia al imperativo moral. De hecho, el Dios del Viejo Testamento - tal como aparece en "Armonía bíblica" - premia con su amor al hombre que cumple con su deber. En este último poema, el elogiado, el héroe José Gálvez, es "...el varón fuerte [que muere] / por su patria y por su ley, / y en su alcázar lo recibe / el Dios Santo de Israel".

La imitación de un lied, "Si yo te amo?", nos muestra a Palma en su manera más romántica, exhibiendo la debilidad de su imaginación y preparando su renuncia a la "poesía", para luego abrazar la enseñanza versificada. En estos versos el poeta invita a su amada a que dude de todo lo cierto antes de dudar de su amor; mandato bastante romántico. Pero, si nos fijamos en lo que se presenta como cierto, descubrimos que se trata de convenciones vacías, muy lejanas de la originalidad exigida por la doctrina romántica, y que tampoco son cosas ciertas. Lo triste es que no hay en el poema señal alguna de que Palma se esté burlando de lo amanerado de su forma.

El poema es tan corto como representativo $y$, por consiguiente, nos es lícito citarlo íntegro:

Duda, querida mía, que presa el ave en riquísima jaula de oro y marfil, libre aspirar anhele la brisa suave, cargada del aroma que da el pensil;

Duda que el peregrino, que, del desierto cruzando va perdido por el erial, hallar ansíe fresco oasis abierto y las aguas dormidas del manantial;

Que de crudas borrascas en los azares de Dios no ame el marino la majestad; que a perderse los ríos van a los mares; duda que amen los pueblos la libertad;

Que en el espacio flotan músicas bellas; que matiz y perfume tiene la flor; duda que rayos lancen astros y estrellas; no dudes de mi amor.

Los pájaros que Palma presenta como amantes de la libertad resultan ser - si se miran con el cuidado que merece cualquier poema- bastante domésticos, pues su libertad consistiría en respirar una "brisa suave" cuyo 
aroma, para aumentar nuestra duda, viene de un jardín que apenas si existe (puesto que está encantado). El pobre peregrino, perdido tanto en la sintaxis como en el erial del desierto, bien puede ansiar el oasis, pero saciada su sed, sigue perdido. El marinero que se encuentra (o se extravía) "de crudas borrascas en los azares", en vez de admirar la majestad de Dios probablemente maldice la falta de visibilidad y ansía su llegada al puerto que es, para él, un oasis. No nos importa cómo reaccionara el propio Palma cuando experimentó una tormenta marina: el poema habla de un marinero genérico y no del poeta específico. Los ríos sí se pierden en el mar, si se personifican primero - se ha hecho desde antes de Jorge Manrique-, y también la neblina sube del mar a la nube para perderse en la lluvia que cae sobre la tierra y llena los ríos. La historia abunda en ejemplos de pueblos que, como el pájato en jaula de oro, prefieren la servidumbre a la libertad si el aire de ésta no es tan suave como "la brisa... / cargada del aroma que da el pensil". Además de "músicas bellas", flotan por el espacio muchos sonidos menos placenteros. Dejaremos su matiz y su perfume a la flor y hasta no nos quejaremos de la personificación de los "astros y estrellas", que en verdad no lanzan nada, aunque el desafío a dudar de todo nos tiente a quitarle a Palma la licencia poética de la que abusa como conductor tan arriesgado y carente de la imaginación que se necesita para salir del peligro.

Así, cuando Palma dice que su amor es más seguro que lo que él califica de real, cree que está brindando a este amor el tributo más alto. Lo que hace, al contrario, es contrastar la convención romántica del amor con las parábolas románticas de la realidad. La expresión de su concepto de la realidad, aunque se presente en términos "poéticos", carece de vigor por su falta de imaginación. De ahí, su desilusión con la poesía. Además, la afirmación de su amor, afirmación que depende para ser cré́ble de la relación que tenga con lo que el poeta cree ser la realidad, sufre a la medida que se revela lo metafórico de esa presunta realidad. Sin embargo, las conjeturas que se exponen en "¿Si yo te amo?" son verdaderas para Palma: por eso las emplea como la medida de su amor. Así, cuando vira hacia el didacticismo, será para animar a los pueblos en su lucha por la libertad.

Como la voz del Señor en "Fatum", Palma predica la libertad y el progreso (sicmpre unidos en el pensamiento romántico-liberal), diciendo "adelante" a la humanidad en poemas tales como " ¡A las armas!" y "Libertad". En este poema, hasta considera a Cristo el profeta de la libertad y asocia el futuro glorioso e inevitable de la humanidad con la gloria celestial. Esta libertad terrenal y a la vez divina se opone a la poesía (to- 
davía sentida como en "Romanticismo") cuando el poeta pregunta a la libertad personificada:

\author{
¿Acaso tú serás poética quimera, \\ sueño ideal? \\ ¿Nunca te elevarás a la sublime esfera \\ de lo real?
}

Palma contesta su propia pregunta, gritando:

\author{
¡No! santa libertad, te han calumniado \\ porque no vieron tu esplendor lucir. \\ ¡Adelante! ¡Se acerca tu reinado... \\ avanza el porvenir!
}

Las palabras "santa" y "reinado" nos recuerdan al Cristo de la segunda estrofa del mismo poema, quien

$$
\begin{gathered}
\text {... a predicar sus mágicas doctrinas } \\
\text { que vietten luz } \\
\text { vino, para alcanzar ceñir su sien de espinas } \\
\text { y hórrida cruz. }
\end{gathered}
$$

Por el contexto, las "mágicas doctrinas" del Salvador incluyen la democracia, demasiado real para ser poética. Dudar de la realidad de la llegada del reino de la libertad es, para Palma, herejía; ignorarla para escribir poesía es blasfemia.

Este concepto del derecho divino de la democracia alcanza su expresión más clara en "Hostia" donde Palma dice que
A la justa y sagrada democracia el Hombre-Dios desde la cruz nos guía.
¡De rodillas! ¡Tu pan de eucaristía
es ella, humanidad!

No nos importa la blasfemia de esta estrofa: lo que nos interesa es la apoteosis liberal de la política (la democracia = la hostia = el cuerpo de Cristo) dentro de un marco de poesía abominable tanto por su falta de imaginación romántica como de ingenio clásico.

El conflicto básico en los poemas de Palma es el de la poesía romántica que él quisiera escribir y no puede, tanto por falta de aptitud como por la inhibición que le impone la conciencia que le llama a cumplir su 
deber cívico. Tal deber sólo lo cumple Palma dentro de la literatura cuando escribe la prosa de sus Tradiciones. ${ }^{2}$

Así no nos debe sorprender el hecho de que Palma se interesara en la poesía de Enrique Heine. Éste muestra un conflicto semejante entre la poesía romántica y la dureza de la realidad (conflicto sintomático de la degeneración del romanticismo que había quetido extender la realidad en ambas direcciones, la imaginativa y la física). Mas en los poemas de Heine -aun en las traducciones de Palma, basadas en las versiones francesas en prosa de Gérard de $\mathrm{Nerval}^{3}$ - el choque es más fuerte porque el poeta alemán tiene una rica imaginación poética que le habilita para oponer la realidad y la poesía en una dialéctica que resulta vital y hace creíble su visión de ambas. ${ }^{4}$

La diferencia entre Heine y Palma puede verse en el "Fragmento I" de aquél:

Rocas, monstruos, oleajes, tempestades;

niña, mi corazón es como el mar;

si a su fondo desciendes

perlas de gran valor encontrarás.

Compárese este poema -que ni se acerca a lo mejor de Heine-- con "Definición" y la superioridad del alemán salta a la vista. En el poema de Palma, las lágrimas son las perlas buscadas por el dolor en el océano del corazón, figura ridícula que hace que las lágrimas resulten porfiadas y gratuitas, pues son consideradas un valor en sí mismas. Así el poeta parece estimar el corazón humano por lo que tiene en común con la cebolla, como ya lo había sentenciado Coleridge, refiriéndose al nuevo teatro burgués. En el poema de Heine, no se dice cuál es el tesoro y la poesía gana en este caso por la falta de especificidad, pues no importa lo que sean las "perlas de gran valor" con tal que no sean aquellas lágrimas autónomas. Además, Heine nos convence de lo apto de su símil del mar y el corazón por haber empezado el poema con una lista de lo que tienen en común: "Rocas, monstruos, oleajes, tempestades".

2 A propósito de este tema, el profesor Luis Monguió -cuya paciencia y ayuda nunca podré agradecer lo bastante- me ha referido a "La bohemia de mi tiempo", en Ricardo Palma, Tradiciones peruanas completas (ed. de Edith Palma), 43 ed. (Madrid, 1961), pp. 1293-1321, especialmente las pp. 1320-1321, donde Palma expresa su convicción de que la poesía es un oficio de jóvenes, los cuales, a la medida que maduran, deben dejarlo para dedicarse a menesteres civicos.

3 Traducciones en Poesias completas, pp. 141-169. Las de Heine están en las pp. 151-152.

4 Aunque es cierto que Heine también cae a veces en el exceso romántico. 
Podríamos citar más ejemplos de la superioridad poética de Heine, pero esto nos alejaría de nuestro propósito de mostrar por qué Heine le interesaba a Palma. El mayor valor poético de aquél es solamente una de las razones de su interés. Al mostrar su superioridad, también hemos visto el lado romántico de Heine que igualmente interesa a Palma y que lleva dentro de sí una reacción hacia el sentido común, pues todos los rasgos del corazón en el poema citado - menos el tesoro anónimo que no forma parte íntegra del corazón - son destructivos.

La conciencia que Heine tenía de los aspectos no románticos de la vida se ve en "Una mujer", cuyo personaje onomástico gozaba de lo ganado por su amante ladrón, pero cuando éste fue preso, " . . ella Rhin bebía / con otro nuevo amador".

Palma se ha equivocado al traducir estos versos, pues quita mucha de la amargura presente en la versión de Nerval, que reza así: Vers six beures du matin il fut pendre, à sept beures on le jeta dans la fosse; mais elle, une beure après, buvait du vin et riait. ${ }^{5}$ En la traducción de Palma, la ironía ha sido suavizada por la eliminación de la prisa, comunicada en su modelo por las repetidas referencias a la hora. También falta a la versión española el mórbido contraste irónico entre la risa y el dogal, pues éste ha sido eliminado. La tercera causa de la pérdida de ironía sufrida al traducir el poema es la ausencia en el texto español de la última repetición de "y reía". Esta frase, además de ser el vehículo más importante para la ironía de Heine, le sirve a éste (y hasta aquí, a Palma también) para tejer los elementos de la anécdota en un diseño que hace arte de la desilusión sentida por el poeta (desilusión que por su tono se diferencia tanto de la melancolía como de la picardía románticas). Esos elementos se subsumen en una totalidad que intensifica la emoción del poema al mismo tiempo que nos aleja de esta emoción, dirigiendo nuestra atención hacia la estructura. Es decir, la realidad de "Una mujer" es también una realidad poética que, por lo tanto, exige ser expresada en términos poéticos.

Ésta es la piedra de toque. La llamada a la realidad en su aspecto de sentido común es tan fuerte en "Una mujer" como en "Romanticismo", pero Heine, aunque rechaza la visión irreal de la vida que se asocia con el romanticismo, no la identifica con la poesía, como sí lo hace Palma. Al contrario, incorpora este rechazo en su poesía.

Así, mientras Palma glorifica la política por identificar la democracia con el Salvador en "Libertad", Heine, en el poema más político (junto con "En Octubre de 1849") de los traducidos por don Ricardo, "Al rey

5 Henti [sic] Heine, Poëmes et légendes (Paris, s.f.), p. 162. 
de Prusia", niega con ironía a Cristo y pone la poesía en el vacío trono divino:

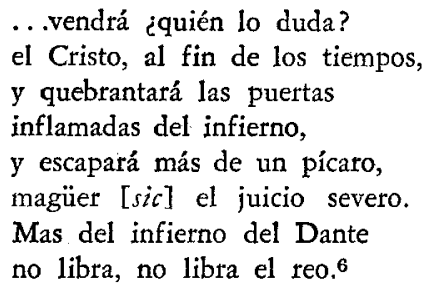

Ambos poetas se enfrentan con la misma problemática: la existencia dentro de su obra poética de una visión que podemos llamar tomántica y de otra que podemos llamar clásico-realista. Heine resuelve el problema al incorporar la contradicción en la textura de su poesía. Palma, para quien la poesía es una extravagancia romántica que le atrae y le repele al mismo tiempo y que él es incapaz de crear, acaba por huir de ella para escribir sermones seculares en verso y la valiosa prosa de las Tradiciones.

University of California,

LEWIS H. RuBMAN

Berkeley

a El texo de Nerval es más fuerte: "Et à la fin des jours, le Christ descendra et brisera les portes de l'enfer, et bien qu'il rende un jugement sévère, plus d. un gaillard en écbappera.

"Ne connais-tu pas l'enfer du Dante, ces terribles tercines? Celui que le poëte y a emprisonné, celui-là, nul Dieu ne peut le sauvre." (Ibid., pp. 269-270). 